\title{
Synthesis of Alkylquinolines by the Reaction \\ of Aniline with Photooxidation Alcohols \\ in the Presence of $\mathrm{FeCl}_{3} \cdot 6 \mathrm{H}_{2} \mathrm{O}$
}

Aynur R. Makhmutov*

Bashkir State University

32 Z. Validi Str., Ufa, 450076, Russia

Received 22.01.2017, received in revised form 14.03.2017, accepted 12.05.2017

The paper presents experimental data on synthesis of the substituted 2,3-dialkylquinolines by the condensation reaction of aniline with photooxidation products of aliphatic alcohols $\left(C_{2}-C_{5}\right)$. The synthesis is a 2-stage process. The first stage is the photo-oxidation of alcohols to aldehydes using $\mathrm{FeCl}_{3} \cdot 6 \mathrm{H}_{2} \mathrm{O}$ under $\mathrm{UV}$ irradiation. The second stage is the condensation of aniline with aldehydes photosynthesized under the effect of the catalyst $\mathrm{FeCl}_{3} \cdot 6 \mathrm{H}_{2} \mathrm{O}$. The influence of nature of the solvent, $\mathrm{pH}$ and the ratio of initial components on the yield of alkylquinolines are investigated. A probable mechanism of photooxidation of alcohols by $\mathrm{Fe}^{3+}$ is proposed.

Keyword: 2,3-dialkylquinolines, 1,1-dialkoxyalkanes, iron trichloride, photooxidation, condensation.

DOI: $10.17516 / 1998-2836-0014$.

(C) Siberian Federal University. All rights reserved

* Corresponding author E-mail address: ainurmax@mail.ru 


\title{
Синтез алкилхинолинов реакцией
}

\section{конденсации анилина с фотооксленными спиртами \\ под действием $\mathrm{FeCl}_{3} \cdot 6 \mathrm{H}_{2} \mathrm{O}$}

\author{
A.P. Махмутов \\ Башкирский государственный университет \\ Россия, 450076, Уфа, ул. 3. Валиди, 32
}

\begin{abstract}
В статье приведены экспериментальные данные по синтезу замещенных 2,3-диалкилхинолинов реакиией конденсации анилина с продуктами фотоокисления первичных алифатических спиртов $\left(C_{2}-C_{5}\right)$. Синтез представляет собой двухстадийный проиесс. Первая стадия фотоокисление спиртов до альдегидов с помощью трихлорида железа $\mathrm{FeCl}_{3} \cdot 6 \mathrm{H}_{2} \mathrm{O}$. Вторая стадия - конденсаиия анилина с фотосинтезированными альдегидами под действием катализатора трихлорида железа $\mathrm{FeCl}_{3} \cdot 6 \mathrm{H}_{2} \mathrm{O}$. Исследовано влияние природы растворителя, pH среды и соотношения исходных компонентов на выход алкилхинолинов. Предложен вероятный механизм фотоокисления спиртов ионом железа (III).
\end{abstract}

Ключевые слова: 2,3-диалкилхинолины, 1,1-диалкоксиалканы, трихлорид железа, фотоокисление, конденсация.

\section{Введение}

Хинолиновые основания относятся к практически важным азотгетероциклическим соединениям [1]. Существуют классические и современные - металлокомплексные - каталитические методы синтеза хинолиновых оснований [2, 3]. Каталитические способы получения востребованных хинолиновых производных с применением комплексов d- и f-металлов (Rh, Pd, Pt, Ru, $\mathrm{Fe}, \mathrm{Pr}, \mathrm{Tb}$ и др.) показали весьма хорошие результаты. Так, например, синтез алкилзамещенных хинолинов конденсацией ариламинов с альдегидами под действием каталитических систем на основе $\mathrm{LnCl}_{3} \cdot 6 \mathrm{H}_{2} \mathrm{O}$ и $\mathrm{FeCl}_{3} \cdot 6 \mathrm{H}_{2} \mathrm{O}$ протекает при комнатной температуре с высоким выходом целевых продуктов $[4,5]$. Однако существенным недостатком данного способа синтеза замещенных хинолинов является применение в качестве исходных реагентов нестабильных карбонильных соединений, легко подвергающихся окислению и самоконденсации при хранении. В связи с этим, предприняты попытки включения в синтез хинолиновых оснований различных спиртов, генерирующих in situ в реакционной смеси продукты окисления - альдегиды. Данный подход впервые успешно реализован в работе [6]. В качестве окислителя спиртов применен четыреххлористый углерод. Высокая селективность по синтезу замещенных хинолинов (конверсия анилина до 100 \% и выход хинолинов до 96 \%) обнаружена для катализатора кристаллогидрата трихлорида железа при дробной загрузке реагентов. Условия реакции: автоклав, температура $140{ }^{\circ} \mathrm{C}$, общее время 4 ч.

В данной работе представлены результаты по каталитическому синтезу алкилзамещенных хинолинов конденсацией анилина с фотоокисленными спиртами. В роли фотоокислите-

$$
-155-
$$


ля первичных алифатических спиртов, а также катализатора синтеза замещенных хинолинов применялся кристаллогидрат трихлорида железа $\mathrm{FeCl}_{3} \cdot 6 \mathrm{H}_{2} \mathrm{O}$.

Фотоокислительная способность кристаллогидрата $\mathrm{FeCl}_{3} \cdot 6 \mathrm{H}_{2} \mathrm{O}$ по отношению к спиртам обнаружена нами ранее в работе [7]. В нашей лаборатории протестирован ряд солей трехвалентного железа в качестве окислителей спиртов при УФ-облучении. Эффективным фотоокислителем оказался хорошо растворимый в спиртах кристаллогидрат $\mathrm{FeCl}_{3} \cdot 6 \mathrm{H}_{2} \mathrm{O}$. Фотоокислительный эффект водного раствора низкомолекулярных соединений железа (III) связывают в первую очередь с образованием гидроксильных радикалов при УФ-облучении $\left(\lambda_{\max }=240\right.$ нм) гидратного комплекса: $\mathrm{Fe}\left(\mathrm{H}_{2} \mathrm{O}\right)^{3+}+\mathrm{h} v \rightarrow \mathrm{Fe}^{2+}+\mathrm{OH}^{-}+\mathrm{H}^{+}$[8]. Такая фотогенерация окислителя носит название реакция фото-Фентона и широко применяется как дополнение к классической реакции Фентона для окислительного разрушения органических загрязнителей [9].

Высокая каталитическая активность $\mathrm{FeCl}_{3} \cdot 6 \mathrm{H}_{2} \mathrm{O}$ в синтезе хинолиновых производных была описана выше. Кроме этого, доступность и дешевизна кристаллогидрата $\mathrm{FeCl}_{3} \cdot 6 \mathrm{H}_{2} \mathrm{O}$ являются важными преимуществами.

\section{Экспериментальная часть}

Исходные реагенты: этанол $\left(\mathbf{C}_{2} \mathbf{H}_{5} \mathbf{O H}\right.$ или $\left.\mathbf{E t O H}\right)$, пропанол-1 $\left(\mathbf{C}_{3} \mathbf{H}_{7} \mathbf{O H}\right)$, бутанол-1 $\left(\mathbf{C}_{4} \mathbf{H}_{9} \mathrm{OH}\right)$, изобутанол $\left(i-\mathbf{C}_{4} \mathbf{H}_{9} \mathrm{OH}\right)$, амиловый спирт $\left(\mathbf{C}_{5} \mathbf{H}_{11} \mathrm{OH}\right)$, изоамиловый спирт $\left(i-\mathbf{C}_{5} \mathbf{H}_{11} \mathbf{O H}\right)$, анилин, этилацетат, диэтиловый эфир, ДМФА, ДМСО - коммерческие реагенты. Перед экспериментами реагенты предварительно перегонялись согласно стандартным методикам [10, 11]. Кристаллогидрат трихлорида железа $\mathrm{FeCl}_{3} \cdot 6 \mathrm{H}_{2} \mathrm{O}$ марки «Ч» является коммерческим и не подвергался дополнительной очистке.

Фотоокисление спиртов проведено в фотокаталитической установке Photo Catalytic Reactor Lelesil Innovative Systems с кварцевым реактором объемом на 500 мл (фотореактор типа Штромейера с магнитной мешалкой). В реактор вносили навеску кристаллогидрата $\mathrm{FeCl}_{3} \cdot 6 \mathrm{H}_{2} \mathrm{O}$ и растворяли в соответствующем спирте или водно-спиртовой смеси. Источником излучения служила ртутная лампа среднего давления мощностью $250 \mathrm{~W}$. Спектральный состав излучения: $48 \%$ - УФ-области, $43 \%$ - видимой области и $9 \%$ - ИК-области. Световой поток достигал реакционную систему, проходя через водный слой, термостатируемый при температуре $20^{\circ} \mathrm{C}$. Продолжительность фотоокисления спиртов составляет 60 мин. Время процесса установлено согласно кинетическим параметрам фотовосстановления иона железа (III), определенным спектрофотометрическим методом при $\lambda_{\max }=206$ нм [7]. Продукты фотоокисления спиртов (или водно-спиртовых смесей) отделялись от водного раствора с помощью экстракции этилацетатом на делительной воронке. Экстракт (верхний органический слой) подвергался хроматографическому анализу и после обработки $0,1 \mathrm{M}$ раствором $\mathrm{NaOH}$ направлялся в реакцию конденсации.

Реакция конденсации анилина с фотоокисленными спиртами проводилась в конической колбе объемом 250 мл при интенсивном перемешивании с помощью магнитной мешалки в течение 10 мин. Для этого в колбе предварительно растворялась навеска кристаллогидрата $\mathrm{FeCl}_{3} \cdot 6 \mathrm{H}_{2} \mathrm{O}$ в соответствующем растворителе (ДМФА, ДМСО, этанол, вода) и приливался анилин. К полученному гомогенному раствору вносили этилацетатный экстракт продуктов фотоокисления спиртов (или водно-спиртовых смесей).

$$
-156-
$$


Реакция конденсации экзотермична и завершается в течение 10 мин. После окончания реакции проведена экстракция диэтиловым эфиром. С помощью делительной воронки отделялась верхняя органическая фаза, сушилась безводным сульфатом магния и после отгонки экстрагентов (диэтилового эфира и этилацетата), остаток фракционировался в вакууме (10 мм рт. ст., $\left.20^{\circ} \mathrm{C}\right)$.

Для идентификации продуктов реакции применялся газовый хроматомасс-спектрометр GCMS-QP2010S Ultra фирмы SHIMADZU (Колонка Restek Rtx-5MS, 30 m x 0.25 mm ID, 0.25 um $\mathrm{df})$. Анализ количественного содержания продуктов фотоокисления спиртов в этилацетатном экстракте осуществлен аппаратно-программным комплексом на базе хроматографов ХроматекКристалл 5000.1 и 5000.2 (Колонки Agilent Technologies 19091F-413 HP-FFAP, 30 m x 0.32 mm, 0.25 Micron; Analytical Science $30 \mathrm{~m}$ x $0.32 \mathrm{~mm}$ ID-BPS, $0.5 \mathrm{um}$ ).

\section{Обсуждение результатов}

Разработанный каталитический синтез алкилзамещенных хинолинов конденсацией анилина с фотоокисленными спиртами разделен на две стадии. На первой стадии алифатические первичные спирты подвергаются фотоокислению с помощью кристаллогидрата трихлорида железа под действием УФ-излучения. На второй стадии осуществляется непосредственно синтез целевых продуктов - алкилзамещенных хинолинов каталитической циклизацией анилина с продуктами фотоокисления спиртов, содержащих альдегиды. Рассмотрим каждую стадию по отдельности.

Фотоокисление первичных алифатических спиртов. В процессе фотоокисления первичных алифатических спиртов под действием растворенного в спирте трихлорида железа образуется смесь продуктов, содержащая альдегиды, карбоновые кислоты, сложные эфиры и 1,1-диалкоксиалканы. Функцию окислителя в спиртовой системе (условно $\mathbf{F e C l}_{\mathbf{3}}-\mathbf{R O H}$ ) выполняет трихлорид железа $-\mathrm{FeCl}_{3}$, который активируется при УФ-облучении.

Из литературы известно, что на свету в этанольном растворе трихлорид железа окисляет спирт до ацетальдегида [12]. Однако в продуктах фотоокисления системы $\mathrm{FeCl}_{3}$ - $\mathrm{EtOH}$, кроме ацетальдегида (1), нами обнаружено также наличие уксусной кислоты (2), этилацетата (3) и 1,1-диэтоксиэтана (4). Таким образом, реакция фотоокисления этанола в системе $\mathrm{FeCl}_{3}$-EtOH при мольном соотношении компонентов системы $\left[\mathrm{FeCl}_{3}\right]:[\mathrm{EtOH}]=1: 4$ протекает по схеме, представленной на рис. 1. Соотношение продуктов фотоокисления составляет [1]:[2]:[3]:[4] = 1:1:1:4.

Исходный реакционный раствор имеет насыщенную темно-коричневую окраску благодаря ионам железа $\mathrm{Fe}^{3+}$. В процессе фотоокисления этанола происходит восстановление ионов железа в возбужденном комплексе $\left[\mathbf{F e C l}_{3}\right]^{*}$ до двухвалентного состояния и раствор становится прозрачным со светло-желтым оттенком. Кинетические исследования фотоокисления этанола трихлоридом железа (III) изложены в работе [7].

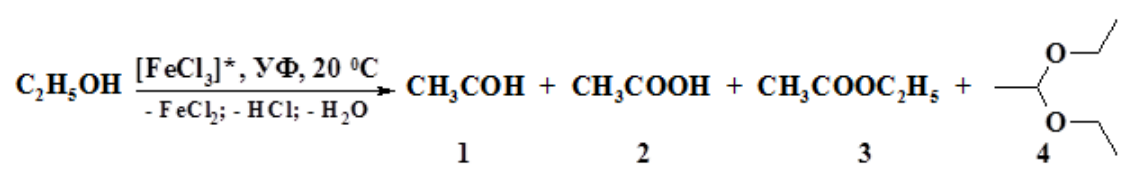

Рис. 1. Схема фотоокисления этанола в системе $\mathrm{FeCl}_{3}-\mathrm{EtOH}$

$$
\text { - } 157 \text { - }
$$


Проведено фотоокисления ряда первичных алифатических спиртов $\mathrm{C}_{2}-\mathrm{C}_{5}$ в системе $\mathrm{FeCl}_{3}$ $\mathrm{ROH}$. Состав и выход продуктов фотоокисления приведен в табл. 1.

Как видно из табл. 1, выход образующихся продуктов фотоокисления в системе $\mathrm{FeCl}_{3}-\mathrm{ROH}$ зависит от длины углеводородного радикала. Так, для этанола (табл. 1, п/п 1) наблюдается образование всех четырех продуктов - 1, 2, 3 и 4. Однако уже начиная с пропанола-1 (табл. 1, п/п 2) состав смеси меняется и основным продуктом фотоокисления для остального ряда изученных спиртов являются ацетали - 1,1-диалкоксиалканы (табл. 1, п/п 3-6).

Влияние рН среды на фотоокисление первичных алифатических спиртов. На модельной системе $\mathrm{FeCl}_{3}-\mathrm{EtOH}$ изучено влияние добавок кислоты, воды и щелочи (т.е. изменения $\mathrm{pH}$ среды) на состав и выход продуктов фотоокисления (рис. 2).

Добавление в систему $\mathrm{FeCl}_{3}$-EtOH водного раствора $\mathrm{H}_{2} \mathrm{SO}_{4}$ с $\mathrm{pH}=2$ дает образование гомогенного раствора интенсивно-желтого цвета. В процессе фотоокисления в данной системе избирательно образуются продукты присоединения окисленных форм этанола $-\mathbf{3}$ и $\mathbf{4}$ в соотношении 2:5 (33 и 77 \%) соответственно. При барботировании атмосферного воздуха через систему $\mathrm{FeCl}_{3}$ - $\mathrm{EtOH}$, содержащую серную кислоту, процесс фотоокисления завершается в течение 20-30 мин.

При добавлении в систему $\mathrm{FeCl}_{3}$ - $\mathrm{EtOH}$ дистиллированной воды $(\mathrm{pH}=7)$ процесс фотоокисления протекает с образованием всех четырех продуктов окисления: 1, 2, 3 и 4 в соотношении 8:2:1:1 (65, 18, 7 и 10 \%) соответственно. Как видно, в водно-спиртовой среде проис-

Таблица 1. Фотоокисление спиртов в системе $\mathrm{FeCl}_{3}-\mathrm{ROH}$

\begin{tabular}{|c|c|c|c|c|c|c|}
\hline \multirow{2}{*}{ № ח/ח } & \multirow{2}{*}{ Спирт } & \multicolumn{4}{|c|}{ Соотношение и выход (\%) продуктов реакции } & \multirow{2}{*}{ Примечание } \\
\hline & & $\mathrm{RCOH}$ & $\mathrm{RCOOH}$ & RCOOR' & $\mathrm{RCH}\left(\mathrm{OR}^{\prime}\right)_{2}$ & \\
\hline 1 & Этанол & $\begin{array}{c}1 \\
(17 \%)\end{array}$ & $\begin{array}{c}1 \\
(13 \%)\end{array}$ & $\begin{array}{c}1 \\
(15 \%)\end{array}$ & $\begin{array}{c}4 \\
(55 \%)\end{array}$ & $\begin{aligned} \mathrm{R} & =\mathrm{CH}_{3}, \\
\mathrm{R}^{\prime} & =\mathrm{C}_{2} \mathrm{H}_{5}\end{aligned}$ \\
\hline 2 & Пропанол-1 & $\begin{array}{c}1 \\
(16 \%) \\
\end{array}$ & - & $\begin{array}{c}1 \\
(13 \%) \\
\end{array}$ & $\begin{array}{c}5 \\
(71 \%) \\
\end{array}$ & $\begin{array}{l}\mathrm{R}=\mathrm{C}_{2} \mathrm{H}_{5}, \\
\mathrm{R}^{\prime}=\mathrm{C}_{3} \mathrm{H}_{7}\end{array}$ \\
\hline 3 & Бутанол-1 & $\begin{array}{c}1 \\
(15 \%)\end{array}$ & - & - & $\begin{array}{c}7 \\
(85 \%)\end{array}$ & $\begin{array}{l}\mathrm{R}=\mathrm{C}_{3} \mathrm{H}_{7}, \\
\mathrm{R}^{\prime}=\mathrm{C}_{4} \mathrm{H}_{9}\end{array}$ \\
\hline 4 & i-Бутанол & $\begin{array}{c}1 \\
(16 \%)\end{array}$ & - & - & $\begin{array}{c}7 \\
(84 \%)\end{array}$ & $\begin{array}{l}\mathrm{R}=i-\mathrm{C}_{3} \mathrm{H}_{7} \\
\mathrm{R}^{\prime}=i-\mathrm{C}_{4} \mathrm{H}_{9}\end{array}$ \\
\hline 5 & Амиловый спирт & $\begin{array}{c}1 \\
(13 \%) \\
\end{array}$ & - & - & $\begin{array}{c}7 \\
(87 \%) \\
\end{array}$ & $\begin{array}{l}\mathrm{R}=\mathrm{C}_{4} \mathrm{H}_{9}, \\
\mathrm{R}^{\prime}=\mathrm{C}_{5} \mathrm{H}_{11}\end{array}$ \\
\hline 6 & $i$-Амиловый спирт & $\begin{array}{c}1 \\
(14 \%)\end{array}$ & - & - & $\begin{array}{c}7 \\
(86 \%)\end{array}$ & $\begin{array}{l}\mathrm{R}=i-\mathrm{C}_{4} \mathrm{H}_{9} \\
\mathrm{R}^{\prime}=i-\mathrm{C}_{5} \mathrm{H}_{11}\end{array}$ \\
\hline
\end{tabular}

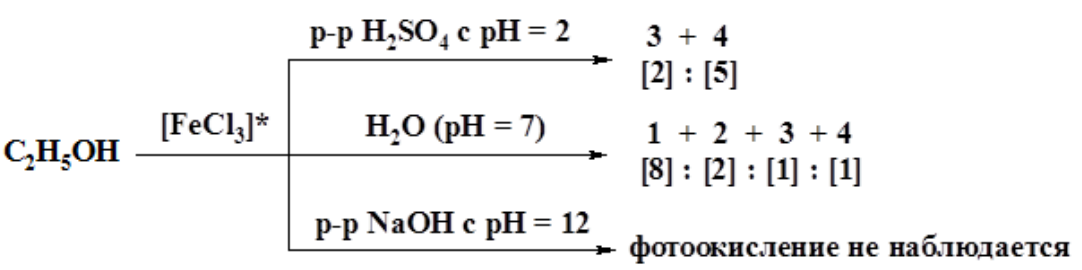

Рис. 2. Влияние $\mathrm{pH}$ среды на процесс фотоокисления этанола в системе $\mathrm{FeCl}_{3}$ - $\mathrm{EtOH}$ 
ходит преимущественно образование альдегида. Барботирование атмосферного воздуха через водно-спиртовую систему $\mathrm{FeCl}_{3}-\mathrm{EtOH} / \mathrm{H}_{2} \mathrm{O}$, содержащую до 50 \% воды, заметного влияния на соотношение продуктов и время фотоокисления не оказывает.

В случае добавления в систему $\mathrm{FeCl}_{3}-\mathrm{EtOH}$ водного раствора $\mathrm{NaOH}$ с $\mathrm{pH}=12$ нарушается гомогенность системы, выпадает красно-коричневый осадок гидроксидов железа. В этих условиях процесс фотоокисления не наблюдается даже при барботировании атмосферного воздуха через реакционный раствор. Основная причина отсутствия процесса фотоокисления в щелочной среде связана с инактивацией фотоокислителя - $\mathrm{FeCl}_{3}$.

Синтез алкилзамещенных хинолинов конденсацией анилина с продуктами фотоокисления спиртов. Высокоэффективным способом получения алкилзамещенных хинолинов является каталитическая реакция конденсации ариламинов с алифатическими альдегидами [13]. Как было показано выше, фотоокисление спиртов и водно-спиртовых смесей в системе $\mathrm{FeCl}_{3}$ $\mathrm{ROH}$ приводит к образованию продуктов окисления, содержащих альдегиды. Поэтому проведена каталитическая конденсация анилина со смесью продуктов фотоокисления спиртов и водно-спиртовых смесей. Экспериментальные данные показали положительный результат.

В качестве катализатора синтеза алкилхинолинов применялся кристаллогидрат $\mathrm{FeCl}_{3} \cdot 6 \mathrm{H}_{2} \mathrm{O}$, растворенный в полярных растворителях (ДМФА, ДМСО, этанол, вода). Влияние природы растворителя и состава продуктов фотоокисленного спирта на выход алкилхинолина изучено на примере модельной реакции конденсации анилина (6) с фотоокисленным пропанолом-1 $\left[\mathbf{C}_{3} \mathbf{H}_{7} \mathbf{O H}_{\text {photoox }}\right]$. Общая схема конденсации имеет следующий вид (рис. 3).

Конденсация протекает при комнатной температуре и атмосферном давлении в течение 10 мин. В качестве продуктов конденсации идентифицированы 2-этил-3-метилхинолин (6) и $\mathrm{N}$-пропиланилин (7).

Обнаружено влияние природы растворителя на конверсию 5 и выход целевого продукта 6. В качестве реакционной среды протестированы следующие полярные растворители: ДМФА, ДМСО, этанол и вода. Результаты представлены в табл. 2.

Влияние природы растворителя на эффективность конденсации понижается в следующем ряду: ДМФА > ДМСО > этанол > вода. Наилучший результат наблюдается для растворителя ДМФА (табл. 2, п/п 1 и 7). Понижение показателей конверсии 5 и выхода 6 в случае растворителей этанола и воды (табл. 2, п/п 5 и 6) связано, в первую очередь, с гидролизом катализатора и выпадением осадка гидроксидов железа, проявляющих малую активность в реакции конденсации.

В среде ДМФА исследовано влияние соотношения исходных компонентов на конверсию 5 и выход целевого продукта 6. Так, в случае конденсации фотоокисленного «безводного» пропанола-1 оптимальное мольное соотношение компонентов составляет $\left[\mathrm{FeCl}_{3} \cdot 6 \mathrm{H}_{2} \mathrm{O}\right]$ :

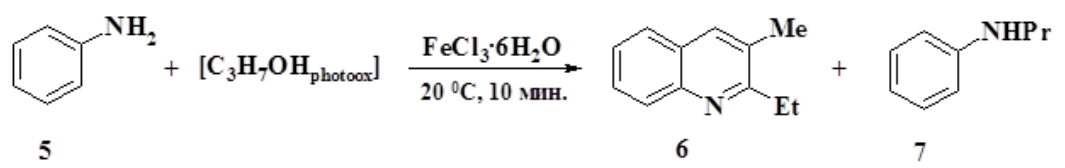

Рис. 3. Схема конденсации анилина с продуктами фотоокисления пропанола-1 под действием $\mathrm{FeCl}_{3} \cdot 6 \mathrm{H}_{2} \mathrm{O}$ 
Таблица 2. Влияние природы растворителя и соотношения исходных компонентов на выход 2-этил-3-метилхинолина

\begin{tabular}{|c|c|c|c|c|}
\hline № п/п & Растворитель & 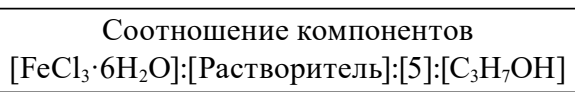 & Конверсия 5, \% & Выход 6, \% \\
\hline \multicolumn{5}{|c|}{ Конденсация анилина (5) с продуктами фотоокисления пропанола-1 } \\
\hline 1 & ДМФА & $1: 200: 50: 1400$ & 58 & 9 \\
\hline 2 & ДМФА & $1: 200: 50: 900$ & 31 & 8 \\
\hline 3 & ДМФА & $1: 200: 50: 400$ & 14 & 9 \\
\hline 4 & ДМСО & $1: 200: 50: 1400$ & 55 & 10 \\
\hline 5 & Этанол & $1: 200: 50: 1400$ & 29 & 6 \\
\hline 6 & Вода & $1: 200: 50: 1400$ & 18 & 4 \\
\hline \multicolumn{5}{|c|}{ 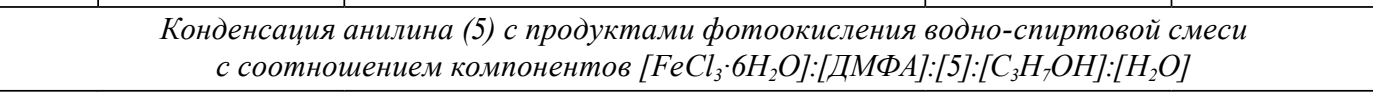 } \\
\hline 7 & ДМФА & $1: 200: 150: 1400: 2500$ & 100 & 65 \\
\hline 8 & ДМФА & 1:200:150:900:1500 & 78 & 62 \\
\hline 9 & ДМФА & $1: 200: 150: 400: 670$ & 54 & 57 \\
\hline
\end{tabular}

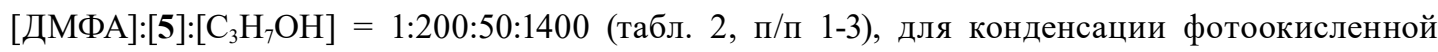
водно-спиртовой смеси $-\left[\mathrm{FeCl}_{3} \cdot 6 \mathrm{H}_{2} \mathrm{O}\right]:[Д М Ф А]:[5]:\left[\mathrm{C}_{3} \mathrm{H}_{7} \mathrm{OH}\right]:\left[\mathrm{H}_{2} \mathrm{O}\right]=1: 200: 150: 1400: 2500$ (табл. 2, п/п 7-9).

Как было указано ранее, фотоокисление водно-спиртовой смеси (рис. 2) протекает с образованием большого количества альдегида по сравнению с фотоокислением чистых спиртов. Следовательно, конденсация $\mathbf{5}$ с фотоокисленным в водной среде пропанолом-1 значительно повышает выход целевого продукта 6 (до 65 \%) при полной конверсии исходного 5 (табл. 2, п/п 7).

Влияние природы фотоокисленных водно-спиртовых смесей на общий выход продуктов фотоокисления-конденсации изучено в среде ДМФА при мольном соотношении исходных компонентов [ $\left.\mathrm{FeCl}_{3} \cdot 6 \mathrm{H}_{2} \mathrm{O}\right]:[Д М Ф А]:[5]:[\mathrm{ROH}]:\left[\mathrm{H}_{2} \mathrm{O}\right]=1: 200: 150: 1400: 2500$. Обобщенная схема фотоокисления-конденсации представлена на рис. 4.

На первой стадии, в процессе стехиометрического фотоокисления водно-спиртовой смеси с помощью трихлорида железа, происходит образование соответствующего альдегида и продуктов, указанных в квадратных скобках на рис. 4 (соответствующая карбоновая кислота, сложный эфир и 1,1-диалкоксиалкан). На второй стадии происходит конденсация анилина с альдегидом, образовавшимся на первой стадии, в присутствии катализатора $\mathrm{FeCl}_{3} \cdot 6 \mathrm{H}_{2} \mathrm{O}$ в среде ДМФА. Продукты, указанные в квадратных скобках - сложные эфиры $(3,11,16$ и 21) и 1,1-диалкоксиалканы $(\mathbf{4}, \mathbf{1 2}, 17$ и 22), в процессе конденсации не участвуют. Для устранения нежелательных побочных реакций (например, взаимодействие анилина или алкилхинолинов с карбоновыми кислотами - 2, 10, 15 и 20) после первой стадии этилацетатный экстракт смеси продуктов фотоокисления спиртов обрабатывается $0,1 \mathrm{M}$ раствором $\mathrm{NaOH}$.

Выход основных продуктов конденсации - алкилхинолинов $(\mathbf{6 , 8 , 1 3}$ и 18$)$ - незначительно снижается с увеличением углеводородного радикала исходных спиртов, т.к. понижается выход соответствующих альдегидов на стадии фотоокисления. Содержание побочных продуктов конденсации - $\mathrm{N}$-алкиланилинов (7, 9, 14 и 19) - находится в пределах 2-3 \%. 


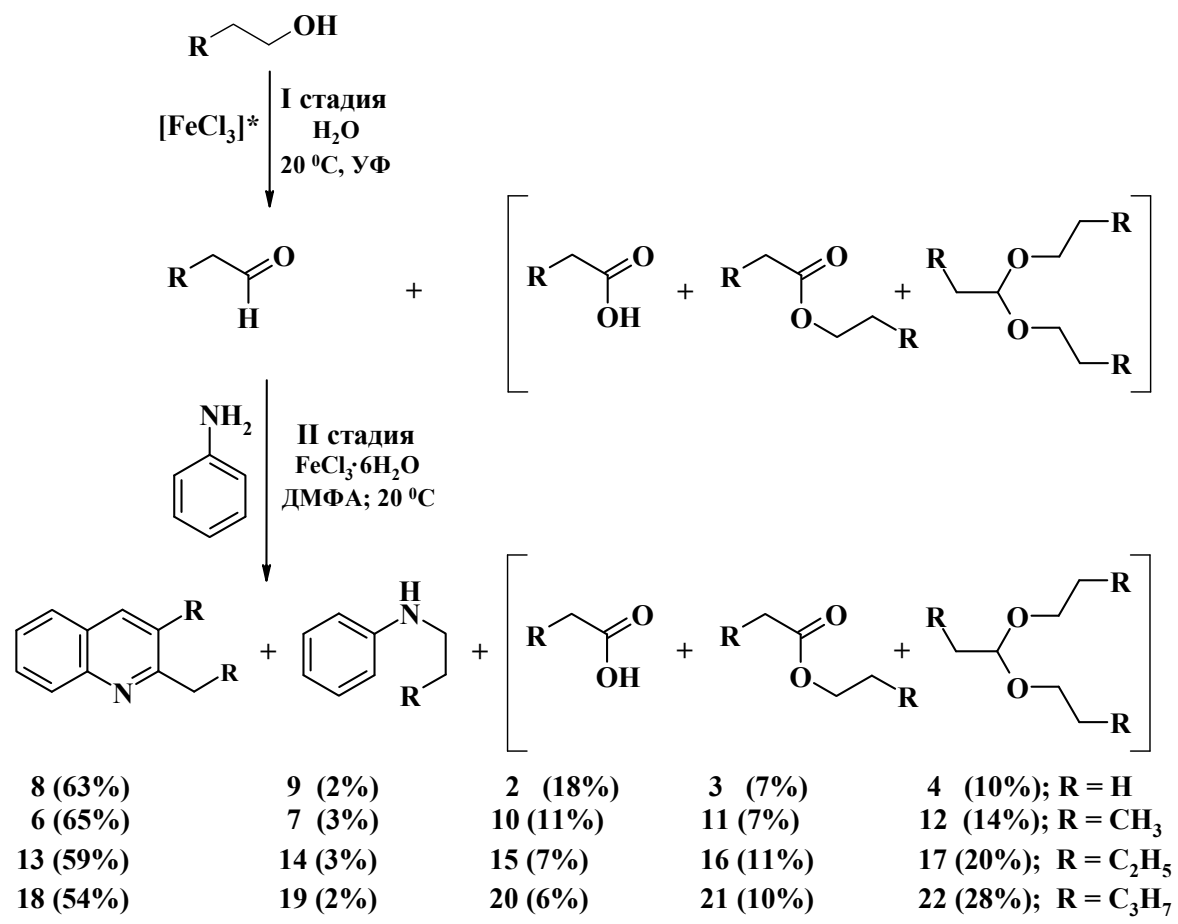

Рис. 4. Общая схема двухстадийной реакции фотоокисления-конденсации

Некоторые аспекты механизма фотоокисления спиртов и каталитической конденсации. Детальное описание постадийного механизма реакции фотоокисления спиртов и конденсации его продуктов с ариламинами будет предметом наших дальнейших исследований. Однако, опираясь на литературные данные, возможно осветить некоторые аспекты механизма действия трихлорида железа как фотоокислителя и катализатора конденсации.

УФ-облучение водно-спиртового раствора трихлорида железа (поглощение излучения в области 200-240 нм для модельной системы $\mathrm{FeCl}_{3}-\mathrm{EtOH}$ ) приводит к фотогенерации гидроксильных радикалов (рис. 5 стадия 1) [7, 8].

Образующиеся гидроксильные радикалы дегидрируют (окисляют) молекулы спирта до альдегида (рис. 5 стадия 2). Среди продуктов окисления наблюдается образование карбоновой кислоты (для модельной системы $\mathrm{FeCl}_{3}$-EtOH содержание уксусной кислоты достигает 18 \%) по реакции дегидрирования (окисления) альдегида гидроксильными радикалами (рис. 5 стадия 3). Формирование 1,1-диалкоксиалканов и сложных эфиров происходит в результате реакции альдегидов и кислот с молекулами спирта (рис. 5 стадии 4 и 5).

Механизм действия катализатора $\mathrm{FeCl}_{3} \cdot 6 \mathrm{H}_{2} \mathrm{O}$ в реакции конденсации альдегидов с анилином, вероятно, аналогичен механизму действия $\mathrm{LnCl}_{3} \cdot 6 \mathrm{H}_{2} \mathrm{O}$, изученному с применением хемилюминесцентного метода в работе [14]. Образование алкилхинолинов происходит через каталитическую циклизацию интермедиатов - оснований Шиффа, продуктов взаимодействия альдегидов с анилином. Некоторая часть азометинов гидрируется (восстанавливаются) в ходе реакции до $\mathrm{N}$-алкиланилинов.

$$
-161-
$$




$$
\begin{aligned}
& \mathrm{Fe}\left(\mathrm{H}_{2} \mathrm{O}\right)^{3+} \stackrel{\mathrm{hv}}{\longrightarrow} \mathrm{Fe}^{2+}+\dot{\mathrm{O}} \mathrm{H}+\mathrm{H}^{+} \\
& \mathrm{CH}_{3} \mathrm{CH}_{2} \mathrm{OH}+2 \dot{\mathrm{OH}} \longrightarrow \mathrm{CH}_{3} \mathrm{COH}+2 \mathrm{HOH} \\
& \mathrm{CH}_{3} \mathrm{COH}+2 \dot{\mathrm{OH}} \longrightarrow \mathrm{CH}_{3} \mathrm{COOH}+\mathrm{HOH} \text { (3) } \\
& \mathrm{CH}_{3} \mathrm{COH}+2 \mathrm{CH}_{3} \mathrm{CH}_{2} \mathrm{OH} \longrightarrow+\mathrm{O}_{-2 \mathrm{HOH}} \\
& \mathrm{CH}_{3} \mathrm{COOH}+\mathrm{CH}_{3} \mathrm{CH}_{2} \mathrm{OH} \longrightarrow \mathrm{CH}_{3} \mathrm{COOC}_{2} \mathrm{H}_{5}+\mathrm{HOH}
\end{aligned}
$$

Рис. 5. Вероятный механизм реакции фотоокисления спиртов на примере модельной системы $\mathrm{FeCl}_{3}$-EtOH в водной среде

\section{Ацетали 1,1-диалкоксиалканы - сопутствующие продукты синтеза алкилхинолинов.} Следует отдельно отметить, что в ходе двухстадийного процесса синтеза алкилхинолинов (рис. 4) образуются сопутствующие продукты фотоокисления спиртов - 1,1-диалкоксиалканы $4,12,17$ и 22, являющиеся перспективными оксигенатными присадками для моторных топлив [15]. Применение 1,1-диалкоксиалканов повышает детонационную стойкость топлив и снижает содержание вредных продуктов сгорания [16].

Помимо перспективных топливных присадок, ацетали являются также растворителями и ароматизаторами в парфюмерии и пищевой промышленности, в медицине - добавками к лекарственным препаратам. Известно применение 1,1-диалкоксиалканов в органическом синтезе [17].

\section{Заключение}

Таким образом, в работе приведены результаты экспериментальных исследований каталитического синтеза алкилзамещенных хинолинов конденсацией анилина с фотоокисленными спиртами под действием $\mathrm{FeCl}_{3} \cdot 6 \mathrm{H}_{2} \mathrm{O}$. Синтез состоит из двух стадий: фотоокисления первичного алифатического спирта и конденсации продуктов фотоокисления с анилином. Основными продуктами синтеза являются практически важные соединения - алкилзамещенные хинолины и 1,1-диалкоксиалканы.

\section{Список литературы}

1. Makhmutov A.R., Mustafin A.G., Usmanov S.M. Catalytic photocyclisation arylamines with $\alpha$-olefins in the synthesis of 2-alkylquinolines. International Journal of Environmental and Science Education 2016. Vol. 11. № 18, P. 11831-11838.

2. Vollhardt K. Peter C. and Neil E. Schore. Organic Chemistry: Structure and Function. New York: W.E. Freeman and Company. 2007, P. 754.

3. Махмутов А.Р., Усманов С.М. Фотосинтез замещенных хинолинов в водной среде. Башкирский химический журнал 2016. Т. 23. № 3, C. 77-79. [Makhmutov A.R., Usmanov S.M. 
Photosynthesis of the substituted quinolones in the water environment. Baskirskii khimicheskii zhurnal 2016. Vol. 23. № 3, P. 77-79 (in Russ.)]

4. Булгаков Р.Г., Кулешов С.П., Махмутов А.Р., Джемилев У.М. Кристаллогидраты $\mathrm{LnCl}_{3} \cdot 6 \mathrm{H}_{2} \mathrm{O}$ - высокоэффективные катализаторы синтеза алкилзамещенных хинолинов и фенантролинов. ЖОрХ 2006. T. 42. № 10, C. 1583-1584. [Bulgakov R.G., Kuleshov S.P., Makhmutov A.R., Dzhemilev U.M. $\mathrm{LnCl}_{3} \cdot 6 \mathrm{H}_{2} \mathrm{O}$ crystal hydrates as highly effective catalysts in the synthesis of alkylsubstituted quinolines and phenanthrolines. Russian Journal of Organic Chemistry 2006. Vol. 42. № 10, Р. 1573-1575 (in Russ.)]

5. Булгаков Р.Г., Кулешов С.П., Вафин Р.Р., Джемилев У.М. Каталитическая активность кристаллогидратов хлоридов $\mathrm{Fe}, \mathrm{Al}, \mathrm{Co}, \mathrm{Mg}$ в реакции конденсации анилина с масляным альдегидом. ЖОрХ 2009. Т. 45. № 6, С. 956-957. [Bulgakov R.G., Kuleshov S.P., Vafin R.R., Dzhemilev U.M. Catalytic activity of iron (III), aluminum (III), cobalt (II) and magnesium (II) chloride crystal hydrates in the condensation of aniline with butyraldehyde. Russian Journal of Organic Chemistry 2009. Vol. 45. № 6, P. 944-945 (in Russ.)]

6. Хуснутдинов Р.И., Байгузина А.Р., Аминов Р.И. Синтез замещенных хинолинов реакцией анилинов со спиртами и $\mathrm{CCl}_{4}$ под действием $\mathrm{Fe}-$ содержащих катализаторов. Известия Академии наук. Серия химическая. 2013. № 1, C. 134. [Khusnutdinov R.I., Bayguzina A.R., Aminov R.I. Synthesis of substituted quinolines by the reaction of anilines with alcohols and $\mathrm{CCl}_{4}$ in the presence of Fe-containing catalysts. Russian Chemical Bulletin 2013. Vol. 62. № 1, P. 133-137 (in Russ.)]

7. Махмутов А.Р., Усманов С.М. Фотоокислительные превращения алифатических спиртов в системе $\mathrm{FeCl}_{3} \cdot 6 \mathrm{H}_{2} \mathrm{O}-\mathrm{ROH}$. Башкирский химический журнал 2017. T. 24. № 1, С. 18. [Makhmutov A.R., Usmanov S.M. Photooxidative conversion of aliphatic alcohols in the systems $\mathrm{FeCl}_{3} \cdot 6 \mathrm{H}_{2} \mathrm{O}-\mathrm{ROH}$. Baskirskii khimicheskii zhurnal 2017. Vol. 24. № 1 (in Russ.)]

8. Feng W., Nansheng D. Photochemistry of hydrolytic iron (III) species and photoinduced degradation of organic compounds. A minireview. Chemosphere 2000. 41, P. 1137-1147.

9. Ruppert G., Bauer R. The photo-Fenton reaction - an effective photochemical wastewater treatment process. Journal of Photochemistry and Photobiology, A.: Chemical 1993. 73, P. 75-78.

10. Беккер Х., Беккерт Р., Бергер В., Гевальд К. и др. Органикум. М.: Мир, 2008. Т. 2. 488 с. [Becker H., Beckert R., Berger V., Geval'd K. Organikum. Moscow: Mir, 2008. Vol. 2. 488 p. (in Russ.)]

11. Вайсбергер А., Проскауэр Э., Риддик Дж., Тупс Э. Органические растворители. М.: Ин. лит-ра, 1958. 518 c. [Weissberger A., Proskauer E., Riddick J., Tups J. Organic Solvents. Moscow: Inostrannaya literatura, 1958. 518 p. (in Russ.)].

12. Карякин Ю.В., Ангелов И.И. Чистые химические вещества. М.: Химия, 1974. С. 108. [Karyakin Y.V., Angelov I.I. Pure Chemicals. Moscow: Khimiya, 1974. P. 108. (in Russ.)]

13. Патент 2309952 РФ. Булгаков Р.Г., Кулешов С.П., Махмутов А.Р., Джемилев У.М. Cnoсоб получения 2,3-диалкилхинолинов. Опубл. 04.05.2006. [Patent 2309952 RU. Bulgakov R.G., Kuleshov S.P., Makhmutov A.R., Dzhemilev U.M. Method of producing 2,3-dialkylquinolines. Publ. Date 04.05.2006 (in Russ.)]

14. Булгаков Р.Г., Кулешов С.П., Махмутов А.Р., Джемилев У.М. О механизме хемилюминесцентной реакции конденсации анилина с масляным альдегидом, катализируемой $\mathrm{LnCl}_{3} \cdot 6 \mathrm{H}_{2} \mathrm{O}$. Кинетика и катализ 2010. Т. 51. № 4, C. 558-565. [Bulgakov R.G., Kuleshov S.P., 
Makhmutov A.R., Dzhemilev U.M. On the mechanism of the chemiluminescent condensation of aniline with butyraldehyde catalyzed by $\mathrm{LnCl}_{3} \cdot 6 \mathrm{H}_{2} \mathrm{O}$. Kinetics and Catalysis 2010. Vol. 51. № 4, P. 534-541 (in Russ.)]

15. Вильданов Ф.Ш., Латыпова Ф.Н., Чанышев Р.Р., Даминев Р.Р., Каримов О.Х., Мамлиева А.В. Производство этилтретбутилового эфира - перспективное направление использования биоэтанола в России. Башкирскийхимическийжурнал 2013. Т. 20. № 3, С. 145-149. [Vil'danov F.Sh., Latypova F.N., Chanyshev R.R., Daminev R.R., Karimov O.H., Mamlieva A.V. Manufacture of ethyltret-butil ether - a perspective direction of use of bioethanol in Russia. Baskirskii khimicheskii zhurnal 2013. Vol. 45. № 6, P. 145-149 (in Russ.)]

16. Патент 2535373 РФ. Брей В.В., Шаранда М.Е., Щуцкий И.В. Одностадийный способ получения 1,1-диэтоксиэтана. Опубл. 26.02.2013. [Patent 2535373 RU. Brej V.V., Sharanda M.E., Shchutskij I.V. Single-Step method of producing 1,1-Diethoxyethane. Publ. Date 26.02.2013 (in Russ.)]

17. Zhang H., Wu Y., Li L., Zhu Z. Photocatalytic direct conversion of ethanol to 1,1-diethoxyethane over noble-metal-loaded $\mathrm{TiO}_{2}$ nanotubes and nanorods. ChemSusChem. 2015. № 8. P. 1226-1231 (doi: 10.1002/cssc.201403305). 